\title{
Opportunistic Intestinal Protozoan Infection Among HIVIAIDS Patients and the Associated Risk Factors in Jalingo Local Government, Taraba State
}

\author{
Onyeuku Okechukwu Chinwe ${ }^{1,}$, , Agbo Oche Joseph ${ }^{2}$, Obiorah Sylvester Chibuzor ${ }^{3}$, \\ Elkanah Obadiah Sambo ${ }^{4}$, Elkanah Deborah Sambo ${ }^{4}$, Ayibatonye Lemmy Orutugu ${ }^{5}$ \\ ${ }^{1}$ Department of Laboratory Services, Taraba State Specialist Hospital, Jalingo, Nigeria \\ ${ }^{2}$ Department of Biological Sciences, Federal University Wukari, Taraba State, Nigeria \\ ${ }^{3}$ Department of Laboratory Services, Federal Medical Centre, Jalingo, Taraba State, Nigeria \\ ${ }^{4}$ Department of Biological Sciences, Taraba State University, Jalingo, Nigeria \\ ${ }^{5}$ Department of Medical Laboratory Science, College of Health Technology, Otuogidi-Ogbia, Bayelsa State, Nigeria
}

Email address:

okechukwuonyeuku66@gmail.com (O. O. Chinwe)

${ }^{*}$ Corresponding author

\section{To cite this article:}

Onyeuku Okechukwu Chinwe, Agbo Oche Joseph, Obiorah Sylvester Chibuzor, Elkanah Obadiah Sambo, Elkanah Deborah Sambo, Ayibatonye Lemmy Orutugu. Opportunistic Intestinal Protozoan Infection Among HIV/AIDS Patients and the Associated Risk Factors in Jalingo Local Government, Taraba State. Central African Journal of Public Health. Vol. 7, No. 4, 2021, pp. 193-197. doi: $10.11648 /$ j.cajph.20210704.17

Received: July 30, 2020; Accepted: August 25, 2020; Published: July 23, 2021

\begin{abstract}
Opportunistic intestinal protozoan parasites are the major contributors affecting HIV/AIDS patients. This study determined the association between intestinal protozoan infection and some predisposing factors among HIV/AIDS patients. Samples were collected from both male and female HIV/AIDS patients and stool samples were also collected from nonHIV/AIDS patients to serve as control. The procedure of wet mount technique and faecal concentration methods processed the faecal materials collected. The $\mathrm{CD}^{4+}$ count of patients were determined using the Partee Cyflow Counter, which determines the percentage of $\mathrm{CD}^{4+}$ cells of individuals. A total of eight hundred and fifty (850) faecal samples were collected from seropositive and sero-negative HIV/AIDS persons in Jalingo metropolis. Out of the 850 subjects, $650(76.47 \%)$ were sero-positive while $200(23.53 \%)$ were sero-negative (Control). The sero-positive subjects showed higher prevalence of $118(18.15 \%)$ of opportunistic parasitic infection according to the follow-up of hospital locations: Government House, 12 (25.71\%); Ummah Clinic, 8 (21.82\%); Taraba State Specialist Hospital, 50 (18.18\%) and Federal Medical Centre, 38 (15.20\%). The prevalence was higher among female positives, $68(19.60 \%)$ than the male, $50(16.50 \%)$ with no significant difference $(\mathrm{p}>0.05)$. The infection based on age groups revealed that the age group 10-15 years had the highest prevalence of $27(48.21 \%)$ while the age group 41-45 years had the least prevalence of $2(2.63 \%)$. There was no significant relationship between age, gender and occurrence of opportunistic intestinal protozoan infection among HIV sero-positive and HIV sero-negative subjects ( $\mathrm{p}>0.05$ ). Analysis on risk factors associated with intestinal protozoan infection revealed that patients whose source of water was from stream are likely to get infected with intestinal protozoans $(\mathrm{OR}=2.95)$ than those who used tap water $(\mathrm{OR}=0.78)$. Based on method of waste disposal, those who practiced open defaecation are at higher risk of infection with intestinal protozoa $(\mathrm{OR}=1.02)$ than those who used water closet system $(\mathrm{OR}=0.30)$. Similarly, those who did not wash hands after toilets are prone to infection $(\mathrm{OR}=2.46)$ than those who frequently was their hands after toilets $(\mathrm{OR}=0.14)$. The public health division in Jalingo metropolis should continue to emphasize the importance of environmental and personal hygiene and collaborate with other Government agencies to provide quality drinking water, good waste management systems, good/faecal disposal systems amongst others to help alleviate the burden of intestinal parasite infections.
\end{abstract}

Keywords: Intestinal, Opportunistic, Parasites, Protozoans, Taraba, Nigeria 


\section{Introduction}

Intestinal protozoan parasites are parasites that infect the gastrointestinal tract of humans and other animals. They can live throughout the body but they prefer the intestinal wall. Protozoans are unicellular organisms and can multiply inside the human body, which can allow serious infection to develop [1].

Opportunistic infections are an infection that occurs more frequently and more severe in individuals with weakened immune system including people with HIV. Therefore an opportunistic infection is an infection caused by pathogens such as bacteria, virus, fungi, helminthes or protozoans that take advantage of an an abnormal opportunity such as a host with a weakened immune system or an altered microbial flora such as a disrupted gut flora [2].

Some of the predisposing factors to getting opportunistic intestinal protozoan parasites include living in, or visiting areas known to have these parasites, intestinal travels, poor sanitation (for both food and water), exposure to child and institutional care center, having a weekend immune system and HIV/AIDS [3]. Opportunistic intestinal protozoan are among the major contributors to the global intestinal parasite load. In different parts of the world a wide variety of intestinal parasites are prevalent.

The Human immune deficiency virus (HIV) is a virus that attacks the immune system which is the body's natural defense against illnesses. A person infected with HIV finds it more difficult to fight infections disease. The viruses destroy white cell called T-helper cells, replicating inside them. Thelper cells are also known as CDs cells. There are two types of HIV: type -1 is the most common type and it is found worldwide. HIV-2 is found mostly in West Africa and in some cases in India and Europe [4]. According to a recent report of News Agency of Nigeria, Rivers State has the highest prevalence (15.2\%) of HIV/AIDS in Nigeria. This was detailed in a report published by national Agency for the Control of AIDS (NACA). Then six months later, Taraba State come second with about $10.5 \%$ prevalence rate while Kaduna State with $9.2 \%$ was in third position. This study determined the association between intestinal protozoan infection and some predisposing factors among HIV/AIDS patients.

\section{Materials and Methods}

\subsection{Study Area}

Jalingo is a city in North-Eastern Nigeria. It is the capital of Taraba State and the headquarters of Jalingo Local Government. The Local Government borders Ardo-Kola in the south, Law Local Government in the North, Yorro Local Government to the East. Districts within Jalingo are Barade, Mayo-Gwoi, Turaki A, Turaki B, Abbare Yelwa, Kachalla sembe, Kona, Majidadi, Sarkin Dawaki and Sintali. Jalingo Local Government is located between latitude $8^{\circ} 89^{\prime} \mathrm{N}$, longitude $11^{\circ} 38^{\prime \prime} \mathrm{E}$.

\subsection{Ethical Permission}

Ethical permission was sought and obtained from Postgraduate review committee of Department of Biological Sciences, Taraba State University, Jalingo. Futhermore, additional permission was sought and obtained from the various hospital management before the commencement of study.

\subsection{Sample Collection}

A total of 650 stool samples were collected from both male and female HIV/AIDS patients and 200 stool samples were also collected from non-HIV/AIDS patients to serve as control. Permission of the parents, hospital and patients was sought for, before the commencement of the study. Each patient was provided with a pre-labelled $60 \mathrm{ml}$ universal sample bottle for stool collection. The patients were instructed on how to collect the sample. The samples were preserved and transported to the laboratory Department of Taraba State Specialist hospital Jalingo, for analysis.

\subsection{Questionnaires'Administration}

A questionnaire relevant to the study was issued to each patient to obtain information on: age, sex, level of education, occupation of parents, and history of previous health status. Qualitative data on environmental/predisposing factor such as type of toilet facility, source of drinking water were obtained from the participants.

\subsection{Microscopic Examination of the Stool}

Two methods of examining the stool were employed as described: the wet mount technique and the concentration technique [5].

The procedure of wet mount technique is as follows: a microscope slide was obtained and one drop of normal saline was placed on one end of the slide. A drop of iodine was placed on the other end to incorporate into the faeces-saline mixture after an initial examination for motile trophozoites. A small amount of the stool was introduced to the drop or saline and another similar specimen into dilute iodine.

Faecal concentration was processed by the sedimentation method. Half tea spoonful of faeces was thoroughly mixed in $10 \mathrm{ml}$ of water and strained through two layer of gauze in a funnel. The filtrate was centrifuged at 2000rpm for 2 minutes, the supernatant was discarded and the sediment was resuspended in $10 \mathrm{ml}$ of physiological saline, centrifuged again and the supernatant discarded. The sediment was re-suspended in $7 \mathrm{ml}$ of formalin saline and allowed to stand for 10 minutes for fixation. About $3 \mathrm{ml}$ of ether was then added. The tube was stoppered and shaken vigorously to mix, then the stopper was removed and the tube was centrifuged at 2000rpm for 2 minutes. The tube was allowed to rest in a stand and four layers became visible. The top layers consisted of ether, second a plug of debris, third a clear layer of formalin saline and the fourth was the sediment. Then the plug of debris was detached from the side of the tube with a glass rod and the 
liquid was poured off leaving a small amount of formalin saline for suspension of the sediment. It was poured on a clean glass slide covered with cover slip and examined under a microscope using $x 40$ objective. The sediment was also mixed with a drop of iodine and examined in the same manner.

\subsection{Statistical Analysis}

Microsoft Excel and SPSS were used to analyze data. Frequency distribution table, percentages, prevalence of infection Attributed to intestinal protozoans in HIV/AIDS patients was estimated. Furthermore, Chi-square test was used to compare infections among sexes, ages and locations. Odds ratio analysis was used to determine the risk factors that are significantly associated with intestinal protozoon infection in HIV/AIDS patients in the study areas. The level of significance was set at $\mathrm{P} \leq 0.05$.

\section{Results}

A total of eight hundred and fifty (850) faecal samples were collected from sero-positive and sero-negative HIV/AIDS persons in Jalingo metropolis. Out of the 850 subjects $650(76.47 \%)$ were sero-positive while $200(23.53 \%)$ were sero-negative (Control), the sero-positive subject showed higher prevalence of 118 (18.15\%) of opportunistic parasitic infection according to the following hospital locations; Govt. House 12 (25.71\%), Ummah Clinic 8 (21.82\%) Taraba State Specialist Hospital, 50 (18.18\%) and Federal Medical Centre, 38 (15.20\%) in decreasing order of prevalence. Sero-negative subjects on the other hand showed lower prevalence $15(7.50 \%)$. In comparison to the HIV positive subjects in this order: Taraba State Specialist Hospital, 6 (8.00\%); Federal Medical center (FMC), 6 $(8.00 \%)$; Govt. House, $2(6.67 \%)$ and Ummah Clinic 2 $(6.67 \%$ respectively (Table 1$)$. The analysis revealed that there is no relationship between the occurence of opportunistic intestinal protozoan infection among HIV seropositive and HIV sero-negative subjects in the selected Health centres in Jalingo $\left(\chi^{2}=14.06 \mathrm{p} \geq 0.05\right)$.

Table 1. Prevalence of Opportunistic Intestinal Protozoan Infection among HIV sero-positive and HIV sero-negative subjects in Jalingo based on Health centres.

\begin{tabular}{|c|c|c|c|c|c|c|}
\hline \multirow{2}{*}{ Health Location } & \multicolumn{2}{|c|}{ HIV Sero-positive } & \multicolumn{2}{|c|}{ HIV Sero-negative } & \multicolumn{2}{|l|}{ Total } \\
\hline & No. Examined & No. infected (\%) & No. Examined & No infected (\%) & No. Examined & No. infected (\%) \\
\hline TSSH JAL. & 275 & $50(18.18)$ & 75 & $6(8.00)$ & 350 & $56(16.00)$ \\
\hline FMC JAL. & 250 & $38(15.12)$ & 50 & $4(8.00)$ & 300 & $42(14.00)$ \\
\hline GOVT. HOUSE & 70 & $12(25.71)$ & 30 & $2(6067)$ & 100 & $20(20.00)$ \\
\hline UMMAH CLINIC & 55 & $8(21.82)$ & 45 & $3(6.67)$ & 100 & $15(15.00)$ \\
\hline TOTAL & 650 & $118(18.15)$ & 200 & $15(7.50)$ & 850 & $133(15.65)$ \\
\hline
\end{tabular}

Key

$\mathrm{GHC}=$ Govt. House clinic

$\mathrm{UMC}=$ Ummah Clinic

TSSH JAL. $=$ Taraba State Specialist Hospital Jalingo.

$\mathrm{FMC}=$ Federal Medical Centre.

Table 2 shows the age and gender specific prevalence of opportunistic intestinal protozoan among HIV in positive patients which reveals that, the prevalence was higher among female positives $68(19.60 \%)$ than the male $50(16.50 \%)$; there was no statistically significant difference $(\mathrm{p}>0.05)$. On the other hand, the occurrence of intestinal protozoan infection based on age group revealed that the age group between 10-15 years had the highest prevalence of 27
(48.21\%), followed by 26-30 years age group had 18 $(28.13 \%)$ the least prevalence of $2(2.63 \%)$ was recorded among 41-45 years in a decreasing order respectively. The Chi-square analysis revealed that there is relationship between age and gender and the occurrence of opportunistic intestinal protozoan infection among HIV sero-positive and HIV sero-negative subject at $p \leq 0.05$.

Table 2. Age and Gender Specific Infections of Intestinal protozoan in HIV Subject in study area.

\begin{tabular}{|c|c|c|c|c|c|c|}
\hline \multirow{2}{*}{ Age (Years) } & \multicolumn{2}{|l|}{ Male } & \multicolumn{2}{|l|}{ Female } & \multicolumn{2}{|l|}{ Total } \\
\hline & No. Exam & No. inf (\%) & No. Exam & No. inf $(\%)$ & No. exam & No. inf (\%) \\
\hline $10-15$ & 33 & $12(36.36)$ & 23 & $15(65.21)$ & 56 & $27(48.21)$ \\
\hline $16-20$ & 33 & $7(21.21)$ & 42 & $11(26.19)$ & 75 & $18(24.0)$ \\
\hline $21-25$ & 29 & $7(24.13)$ & 42 & $8(19.04)$ & 71 & $15(21.13)$ \\
\hline $26-30$ & 34 & $11(32.35)$ & 30 & $7(23.33)$ & 64 & $18(28.13)$ \\
\hline $31-35$ & 47 & $4(8.51)$ & 54 & $11(20.37)$ & 101 & $15(14.85)$ \\
\hline $36-40$ & 41 & $3(7.32)$ & 54 & $6(11.11)$ & 95 & $9(9.47)$ \\
\hline $46-50$ & 32 & $2(6.25)$ & 40 & $4(10.0)$ & 72 & $6(8.33)$ \\
\hline 51 above & 21 & $3(14.28)$ & 19 & $5(26.32)$ & 40 & $8(20.00)$ \\
\hline TOTAL & 303 & $50(16.50)$ & 347 & $68(19.60)$ & 650 & $118(18.15)$ \\
\hline
\end{tabular}

The analysis of risk factors associated with intestinal protozoan infection among HIV/AIDS patients is presented in Table 3. Patients whose source of water is from the stream are likely to be infected with intestinal protozoan parasites 
$(\mathrm{OR}=2.95)$ than those who used tap water $(\mathrm{OR}=0.78)$. Based on waste disposal system, those who practiced open defaecation are at higher risk of infection with intestinal protozoans $(\mathrm{OR}=1.02)$ than those used water closet system
$(\mathrm{OR}=0.30)$. Similarly, those who do not wash hands after toilets are prone to infection $(\mathrm{OR}=2.46)$ than those who frequently wash their hands after toilets $(\mathrm{OR}=0.14)$.

Table 3. Risk Factors Associated with Opportunistic Intestinal Protozoan Infection in HIV/AIDS Patients in Jalingo Metropolis.

\begin{tabular}{|c|c|c|c|c|c|}
\hline Risk Factor & Respondent & No. Examined & No. positive (\%) & OR & P-value \\
\hline \multirow{3}{*}{ Source of water } & Stream & 168 & $53(31.55)$ & 2.95 & \multirow{3}{*}{0.03} \\
\hline & Well & 291 & $35(12.03)$ & 0.45 & \\
\hline & Tap/bore hole & 191 & $30(15.71)$ & 0.78 & \\
\hline \multirow[t]{2}{*}{ Waste disposal } & Bush/open & 270 & $70(45.56)$ & 2.68 & \multirow[t]{2}{*}{0.02} \\
\hline & Water closet system & 182 & $14(15.93)$ & 0.30 & \\
\hline \multicolumn{6}{|l|}{ Hygiene practice } \\
\hline Washing fruits before eating & Yes & 455 & $83(18.24)$ & 0.98 & 0.03 \\
\hline \multirow{2}{*}{ Washing of hands after toilet } & No & 444 & $97(21.85)$ & 2.46 & \multirow{2}{*}{0.01} \\
\hline & Yes & 206 & $21(10.19)$ & 0.14 & \\
\hline
\end{tabular}

\section{Discussion}

HIV/AIDS is a leading public health challenge in Africa especially in Nigeria which has huge population. Prevalence of opportunistic intestinal parasites are common features in HIV sero-positive individuals where majority of AIDS patients die of AIDS related infection including those due to intestinal protozoan parasites rather than the HIV infection itself as it is revealed in this present study. HIV virus suppresses the immunity of individuals and results in the reduced immune response against other pathogens. Therefore HIV infected subjects become at high risk of acquiring intestinal protozoan infection. The result from this study showed a moderate prevalence $(18.15 \%)$ of intestinal parasitic infections in the study area. Amoebiasis, Giardiasis and Cryptosporodiasis are among the most commonly diagnosed intestinal parasites from the study participants. This prevalence was lower in comparison to the $45.3 \%$ and $47.5 \%$ reported respectively by Teklay et al. [6] in Ethiopia and Wumba et al. [7] in DR Congo.

Entamoeba coli and Entamoeba histolytica infections were highly prevalent intestinal protozoan parasites along with Giardia lamblia. This is probably due to the shortage of safe drinking water in most part of Jalingo metropolis. The occurrence of these parasites among HIV/AIDS patients is similar to the research work carried out elsewhere in Africa [7].

Intestinal protozoan infection was found highest in age groups between $10-15$ years old. It is this age category that HIV cases and intestinal parasites was a common occurrence in the population studied. However, the high infection rate was also observed among the age groups 16-30 years and 51 years. Nonetheless, the difference in the observed and prevalence was not statistically significant. The incidence could largely be due to the lack of safe, potable drinking water, poor hygienic and sanitary conditions. It is important to note that the prevalence (90\%) observed among HIVinfected patients is in disagreement agreement with the work of Akinbo et al. [8].
The result of our investigation in this study shows that, there was no significant difference $(\mathrm{P}>0.05)$ in prevalence of infection between male and female subjects. However infection was found higher in females than male examined. This is probably due to the fact that females are usually, exposed to intestinal protozoan parasites compared to their male counterparts based on occupational ground such as engagement in numerous household chores constant contact with contaminated water and soil. This finding is consistent with the previous report of Olapade and Idowu [9] who stated that females are usually exposed to intestinal protozoan parasites than males based on occupational grounds such as their engagement in numerous household chores. Constant contact with contaminated water and contaminated soil equally exposed them to intestinal parasites.

Participants whose sources of water were streams/river were three times more likely to be infected with one or more intestinal parasites as compared to those using tap water because of contamination from human activities such as defaecation, washing and swimming. Similar results were found in studies conducted respectively in Ethiopia and in Nigeria by Gebre et al. [10] and Akinbo and Omoregie [8]. River sand unprotected water is highly contaminated with animals and human excreta since people usually wash their clothes or do laundry in those streams and rivers. These habits have been practiced in developing countries particularly in Nigeria due to scarcity of inadequate distribution of safe/clean water. Using untreated/unsafe water contributes to parasitic infections with one or more intestinal parasitic infections [11-13]. The most prealent waterborne intestinal parasites producing diarrhea are cryptosporidiosis, giardiasis, and amoebasis the parasitic infections have been commonly) reported in immunocompromised patients Particularly in HIV/AIDS patients [14, 15].

The analysis of risk factors associated with intestinal protozoan infection showed that patients whose sources of water is from the stream $(\mathrm{OR}=2.95)$ and those who do not wash hands after toilet were more exposed to parasitic infections. Those exposures could be the lack of clean water to be used and their unhygienic manner to keep themselves 
so clean to avoid intestinal parasites.

\section{Conclusion}

The study reported the prevalence of intestinal parasites among HIV/AIDS patients with special emphasis on the seropositive status of the infected subjects and the intestinal protozoan infections according to demographic indices. The study found the overall prevalence of $18.15 \%$ opportunistic intestinal protozoan infection in sero-positive HIV/AIDS subjects in Jalingo metropolis. Streams, Bush/Open defaecation and not washing hands after toilet and fruits before eating were the major risk factors associated with the contraction of opportunistic intestinal protozoan parasites in Jalingo metropolis. The public health division in Jalingo metropolis should continue to emphasize the importance of environmental and personal hygiene and collaborate with other Government agencies to provide quality drinking water, good waste management systems, good garbage/faecal disposal systems amongst others to help alleviate the burden of intestinal parasite infections. There is the need for the Government to provide anthelminthic and anti-protozoan drugs as part of the drug regimen to treat specific intestinal parasites which are known to coexist in HIV/AIDS conditions.

\section{References}

[1] Obateru, O. A., Bojuwoye, B. J., Olokoba, A. B., Fadeyi, A. F., Olokoba, L. B. Prevalence of intestinal parasites in newly diagnosed HIV/AIDS patients in Ilorin, Nigeria. Alexandria Journal of Medicine, 2017; 53 (2): 111-116.

[2] Alemu G, Alelign D, Abossie A. Prevalence of Opportunistic Intestinal Parasites and Associated Factors among HIV Patients while Receiving ART at Arba Minch Hospital in Southern Ethiopia: A Cross-sectional Study. Ethiop J Health Sci. 2018; 28 (2): 147-156. doi: 10.4314/ejhs.v28i2.6.

[3] Akinbo F O, Anate P J, Akinbo D B, Omoregie R, Okoosi S, Abdulsalami A, Isah B. Risk factors of intestinal parasitic infections among human immunodeficiency virus-infected patients on highly active antiretroviral therapy. Port Harcourt Med J, 2017; 11: 15-20.

[4] Gupta, K., Bala, M., Deb, M., Muralidhar, S. and Sharma, D. K. (2013). Prevalence of intestinal parasitic infections in HIV -infected individuals and their relationship with immune status. Indian Journal of Medical Microbiology, 31: 161-165.

[5] Cheesbrough, M. (2012). District laboratory practice in tropical countries. New York-Cambridge Press. Part 1, $2^{\text {nd }}$ Edition 249-258.
[6] Teklay, G., Haftom, K., Abebaw, A. G. Intestinal parasites among HIV/AIDS patients attending University of Gondar Hospital, northwest Ethiopia. Ethiop. J. Health Dev. 2019; 33 (2): 64-72.

[7] Wumba, R., Longo-Mbenza. B., Mandina, M., Odio, W. T., Biligui, S. and Sala, J. (2010). Intestinal parasites infections in geospitized AIDS patients in Kinshasa, Democratic Republic of Congo. Parasite, 17: 321-328.

[8] Akinbo, F. O. and Omoregie, R. Intestinal parasitic infections in human-immunodeficiency-virus-infected persons on highly active antiretroviral therapy in Benin City, Nigeria. Gen. Med Bio Hlth Sc 2011; 3 (3-4): 119-122.

[9] Olopade BO, Idowu CO. Intestinal parasites among HIVinfected patients at obafemi awolowo university teaching hospitals complex, Ile-Ife. Ann Trop Pathol 2017; 8: 34-8.

[10] Gebre B, Alemayehu T, Girma M, Ayalew F, Tadesse BT, Shemelis T. Cryptosporidiosis And Other Intestinal Parasitic Infections And Concomitant Threats Among HIV-Infected Children In Southern Ethiopia Receiving First-Line Antiretroviral Therapy. HIV AIDS (Auckl). 2019; 11: 299-306. Published 2019 Nov 15. doi: 10.2147/HIV.S215417.

[11] Opoku YK, Boampong JN, Ayi I, et al. Socio-Behavioral Risk Factors Associated with Cryptosporidiosis in HIV/AIDS Patients Visiting the HIV Referral Clinic at Cape Coast Teaching Hospital, Ghana. Open AIDS J. 2018; 12: 106-116. doi: 10.2174/1874613601812010106.

[12] Laksemi DA, Suwanti LT, Mufasirin M, Suastika K, Sudarmaja M (2020) Opportunistic parasitic infections in patients with human immunodeficiency virus/acquired immunodeficiency syndrome: A review, Veterinary World, 13 (4): 716-725.

[13] Ojuromi OT, Ashafa AO. Cryptosporidiosis in Southern Africa: Review of prevalence and molecular epidemiology of a neglected disease. Ann Trop Med Public Health 2018; 11: 10818.

[14] Sinyangwe, T. N., Siwila, J., Muma, J. B., Chola, M., Michelo, C. Factors Associated With Cryptosporidium Infection Among Adult HIV Positive Population in Contact With Livestock in Namwala District, Zambia. Front. Public Health 8: 74. doi: 10.3389/fpubh.2020.00074.

[15] Barcelos, N. B., Silva, L. Freitas., Dias, R. F. G., Menezes, F. H R., Rodrigues, R. M. Opportunistic and non-opportunistic intestinal parasites in HIV/ AIDS patients in relation to their clinical and epidemiological status in a specialized medical service in Goiás, Brazil. Rev. Inst. Med. trop. S. Paulo [Internet] 2018 [cited 2020 Aug 18]; 60: e13. Available from: http://www.scielo.br/scielo.php?script=sci_arttext\&pid=S003646652018005000206\&lng=en. Epub Mar 08, 2018. https://doi.org/10.1590/s1678-9946201860013. 